\title{
Awareness of cloud-based library management software (LMS) in VTU engineering college libraries
}

\author{
C. T. Kantharaja ${ }^{1 *}$, Bharathi. $V^{2}$ \\ ${ }^{1}$ Librarian, ${ }^{2}$ Chief Librarian, ${ }^{1}$ Cambridge Institute of Technology, K.R.Puram, Bangalore, Karnataka, ${ }^{2}$ K.S. Institute of Technology, \\ Raghuvanahalli,, Bangalore, Karnataka, India \\ *Corresponding Author: C. T. Kantharaja \\ Email: ctkantharaj@gmail.com
}

\begin{abstract}
Evolution of Information Communication Technology (ICT) trigger the development of many new technologies. Internet and cloud computing are few among them. Invasion of ICT and its applications inspired the librarians to automate libraries and provide good services to their stakeholders. Library automation is a giant leap in the library science filed. It speedup the process of in-house activities and increase the effectivity in library services. Cloud computing is the recent development in communication field. Latest development is entire world is embracing cloud computing and libraries are not exceptional. Cloud-based library management software is a cost effective, work effective to provide good services to the library users in academic libraries.
\end{abstract}

Keywords: Cloud computing, Library Management Software, Cloud-based ILMS.

\section{Introduction}

The education world has witnessed immense and dynamic developments in the field of academic libraries in the recent days. Libraries play a significant role in the higher education system by enabling the resources to reach the end user. Libraries are in the stage of rapid transition from conventional set up to the modern outlook by enabling new technologies. In India, academic libraries have blended their approach to serve both in digital and traditional formats. The major difference between traditional and modern libraries are lying in the type of collection of resources and their mode of information dissemination to their stakeholders. Now libraries have become a hub in educational institutions for teaching and learning activities wherein faculty, research scholars and students can explore huge information resources. The invasion of Information Communication Technology (ICT) brought many changes and unlimited opportunities in academic libraries to automate and disseminate information through cloud applications. Drastic changes have been witnessed in the field of library automation and library networking as per the requirement of the current trends present in the education system to meet the users' demands and to sustain in the digital world.

\section{Visvesvaraya Technological University (VTU)}

Visvesvaraya Technological University was established on April $1^{\text {st }} 1998$ at Belagavi, a district place in Karnataka, India. The university is named after the great visionary, engineer and eminent states-man Bharat Ratna Sir. M Visvesvaraya. A total number of 218 engineering institutes have been affiliated to VTU. More than 3.5 lakh UG, PG students and Ph.D. scholars are pursuing their degrees in VTU. It has more than 2300 Research \& Development Centers affiliated to it.

\section{Cloud computing}

Cloud computing is an advanced phase of Information Communication Technology (ICT). It facilitates pooling the resources in remote servers and gives access to very large number of computers to access and share the information/resources over the internet. The concept of cloud computing is the improved version of grid computing, wherein thousands of computers are connected each other to share the information, but in cloud computing, thousands of computers are connected to remote, virtualized server, installed somewhere in the world. The service providers maintain these sophisticated, hi-end servers. Most of the giant companies like Amazon, Google, IBM, Salesforce, etc. are involved in this business. The Cloud Service Provider (CSP) connects all his consumer devices with an internet connection to the server. Consumers can access the required type of services they have subscribed by the CSP which can be accessed through a browser or any other intermediate app they provided.

Originally the concept of cloud computing was proposed by a computer scientist John McCarthy at Massachusetts Institute of Technology (MIT) Centennial in 1961, who has also been regarded as the "Forefather of Cloud Computing". John McCarthy in one of his speeches stated that "Computing utility will be on par with telephone utility as quite common for everyone - with simple yet useful benefits" (McCarthy, 1992).

The National Institute of Standards and Technology defines "cloud computing as a model for enabling ubiquitous, convenient, on-demand network access to a shared pool of configurable computing resources that can be rapidly provisioned and released with minimal management effort or with services provider interaction. Cloud computing is a method of availing computer resources from a provider, ondemand by a customer using a computer connected to a network" (Mell \& Grance, 2011).

Based on the various service model, cloud computing is divided into three types. 
1. Infrastructure as a service (IaaS): This kind of cloud services consists of an ample range of various services, features, and resources, which support the organizations to build their cloud infrastructure on demand.

Eg: Amazon Web Services, Google, IBM, HP, etc.

2. Platform as a service (PaaS): This type of cloud services consists of cloud platforms to the organizations or users to maintain their IT infrastructure. The consumers, who wish to save the money and need not spend a huge amount on purchasing hardware, software, related technology, and hence IT infrastructure prefer this model of services.

Eg. Amazon Elastic Cloud, EMC Atmos, etc.

3. Software as a service (SaaS): In this type of cloud service model, already pre-installed customized software would be available with the service provider. Users need not purchase any software or hardware; instead the service provider will manage all these issues. Just users have to pay for using the software application based on a usage basis.

Eg. Email service providers, Google Apps, Salesforce, Microsoft Office 365, etc.

Cloud computing technology did not spare even the libraries from its magnificent influence. Libraries are always at the forefront of adopting new technologies and transformations. Libraries are the main beneficiaries of the Information Technology (IT) as they utilize the technology to a bigger extent and try to adopt the good features of IT as and when technology arrives. Cloud computing technology, which is a boon for libraries, has in turn enabled the libraries to expand their services to the remote users. Most of the western libraries have adopted cloud technology for their in-house activities to provide good services to library stakeholders. However, when we look at Indian libraries, it is a different scenario altogether.

\section{Review of literature}

The word automation has been derived from Greek word 'Automatos' meaning acting of oneself ("Vocabulary.com," 2020). The concept of Library automation was started in the United States, the first attempt of library automation was recorded in the year 1930s. Herman Hollerith invented the punched card technology. Dr. Ralph H Parker used Hollerith Punched card and tried to implement the library circulation system at the University of Texas, Austin ("Library automation," 1996). The development of Information Communication Technology (ICT) in developed countries inspired the librarians to work towards the automation of libraries. In the meantime, library of congress developed Machine Readable Catalogue (MARC) in 1960s. Online Computer Library Centre (OCLC) started a computer-based first library network in the world ("Understanding MARC Bibliographic: Parts 1 to 6," 2005). Microcomputers and storage devices entered the market during 1970s, all these have inspired generation of librarians to automate their libraries at the faster pace. Few libraries have developed their networks for the exchange of bibliographic records through the union catalog of records. L. Kleinrock, an American computer scientist opined that computer networks are in their infancy stage and in future, the field would become more advanced; the sophisticated communication network reaches every corner of the world through wireless technology, then we would probably see the spread of 'computer utilities' in all dimensions of human life (Kleinrock, 2003). Pandya from Sikkim University, India, conducted a detailed study on issues in implementing the library management software on cloud and the services on a SWOT basis. Further, he listed out the strength, weaknesses, opportunities and threats (SWOT), related to cloud computing and libraries (Pandya, 2012).

Nuria Lloret Romero of Polytechnic University of Valencia, Spain expressed that for in case of a small institution, adoption of cloud computing in the name of cost saving and operational efficiency may be very critical. In some other cases, lack of experience or lack of training in technology may increase the fear of losing data, security and privacy issues during cloud computing adoption. Further, the author has stated that one would not be knowing the country, where the virtual server has been installed and also the cloud-computing legislature may be weak and unfavorable to us, all these would end up in trouble. So the author has suggested that, before purchasing the cloud-based application reviewing the service provider's profile is must (Romero, 2012).

Deka Ganesh Chandra et al. have expressed that in case the library server has been installed within the premises, then the entire server maintenance work will come to library professionals along with the other operational duties. In case, the server has been installed on the cloud, the entire responsibilities of server maintenance would be on the shoulders of the service provider, where they would look after the upgradations of software, security patches, etc. the library professionals can concentrate on core activities of library (Chandra, Kathing, \& Kumar, 2013).

In the context of library, the term 'library automation' means using the computer and computer networking to perform in-house library activities in a faster manner with fewer human resources. The cloud-based library management system would reduce the library professionals' workload and engage them in the dissemination of information, attend the user's queries and provide referral and reference services.

\section{Objectives of the study}

1. To study the awareness of cloud computing in librarians.

2. To find out the perception of librarians in adopting the cloud-based library management software.

\section{Methodology}

The survey method is the best method to collect data from a large population. This method was adopted to collect the data from the librarians of VTU engineering college libraries. The tool used to collect the data is the Questionnaire. The questionnaire was designed based on the objectives of the study keeping in mind. It was prepared on an online survey 
tool - JotForm. The survey link was sent to 218 college librarians of all the four regions of VTU. Out of 218 colleges, we have received a good number of responses figuring around 170. The data gathered was analyzed using Microsoft Excel and the results were fruitful. The output gave us some interesting things. The results have been analyzed suitably and presented in the form of tables and charts in the subsequent sections.

\section{Age group of respondents:}

Table 1: Age Group of the respondents.

\begin{tabular}{|c|c|c|c|}
\hline S/N & $\begin{array}{c}\text { Age Group } \\
\text { (in years) }\end{array}$ & Respondents & $\begin{array}{c}\text { Percent } \\
(\mathbf{\%})\end{array}$ \\
\hline 1 & Between 21-30 & 7 & 4.1 \\
\hline 2 & Between 31-40 & 69 & 40.6 \\
\hline 3 & Between 41-50 & 70 & 41.2 \\
\hline 4 & Between 51-60 & 20 & 11.8 \\
\hline 5 & Above 60 & 4 & 2.4 \\
\hline & Total & $\mathbf{1 7 0}$ & $\mathbf{1 0 0 . 0}$ \\
\hline
\end{tabular}

As the librarians working in technical institutes are more exposed to modern gadgets, technologies and applications available in the cloud. They are aware of the informationseeking behavior of techno-savvy library users. In Table 1 . We find the details of the age group of the librarians taken into consideration of the survey and their contribution to the survey in terms of percentage. Between the age of 21-30 contributed least to the survey that is $4.1 \% \quad(n=7)$, next category is of age between 31- 40 years with their contribution of $40.6 \%(n=69)$, next category between $41-50$ years with their contribution $41.2 \%(n=70)$, next age group between 51-60 years with their contribution of $11.8 \%(n=20)$ and finally the age group of above 60 years contributed with their part of $2.4 \%(n=4)$. This table clearly exhibits the age group of 31-40 and $41-50$ years have contributed lot to the survey and helped this study to reach certain valid conclusions.

\section{Awareness of Cloud-based Library Management Software (LMS) in librarians:}

VTU is one of the well-known technical universities in India. A total of 218 technical institutes in Karnataka are affiliated to VTU. It conducts workshops/seminars on many issues related to library automation, content management, institutional repositories, library consortium, etc. to the library professionals to update their technical skills.

Table 2: Awareness of cloud-based LMS

\begin{tabular}{|c|c|c|}
\hline $\begin{array}{l}\text { Awareness of cloud- } \\
\text { based LMS }\end{array}$ & Respondents & $\begin{array}{c}\text { Percent } \\
(\%)\end{array}$ \\
\hline Yes & 110 & 64.70 \\
\hline No & 60 & 35.30 \\
\hline Total & 170 & 100.0 \\
\hline
\end{tabular}

Table 2Fives a handy picture of awareness of cloud-based LMS among librarians. Among 170 librarians, that is around
$64.70 \%(n=110)$ said that they are aware of the cloud-based LMS and nearly $1 / 3$ of the librarians that is around $35.30 \%$ (n = 60) are unaware of the said cloud-based LMS.

Further, the librarians who have answered that they are aware of cloud-based LMS, and were given the option of choosing the cloud-based LMS, suitable for their library. A total of 110 respondents mentioned their choice of opting for the cloudbased LMS.

Table 3: Choice of Cloud-based LMS.

\begin{tabular}{|c|c|c|}
\hline LMS & Responses & Percentage \\
\hline KOHA & 74 & $67.27 \%$ \\
\hline eGranthalaya & 10 & $9.09 \%$ \\
\hline Libsoft & 10 & $9.09 \%$ \\
\hline Libsys & 7 & $6.36 \%$ \\
\hline Easylib & 5 & $4.55 \%$ \\
\hline Librarika & 2 & $1.82 \%$ \\
\hline NewGenLib & 2 & $1.82 \%$ \\
\hline & 110 & $100 \%$ \\
\hline
\end{tabular}

Out of 110 librarians, a good number of librarians with 67.27 $\%(\mathrm{n}=74)$ quoted cloud-based Koha, a fair number of librarians with $6.36 \%(n=7)$ suggested cloud-based Libsys, next group of librarians with $9.09 \%(\mathrm{n}=10)$ cited cloudbased eGranthalaya as their choice, another set of librarians with $1.82 \%(\mathrm{n}=2)$ opted for cloud-based Librarika would fit their library, a small number of librarians with $9.09 \%(\mathrm{n}=$ 10) felt cloud-based Libsoft a suitable LMS, another group of librarians with $4.55 \%(n=5)$ chose Easylib, and finally of $1.82 \%$ respondents $(n=2)$ felt cloud-based NewGenLib software would fit their library.

\section{Suggestions}

As per the suggestions made by the librarians, Koha is one of the free, open-source, library management software. VTU is also conducting workshops to provide hands-on training programmes on Koha. The college managements should think of shifting from the local server to cloud-based LMS. Few cloud vendors have initiated customizing the Koha software as per the requirements and installing it on their cloud. VTU can think of to have a centralized library management software under the VTU Consortium as anyways all engineering college libraries are the member of the consortium by default. The idea of centralized cloudbased LMS may be an acceptable model from all the technical institutes and moreover it would be cost-effective for all the libraries.

\section{Conclusion}

Summary of the survey is that a good number of librarians i.e. of $2 / 3^{\text {rd }}$ joined their hands with this survey are aware of cloud computing and cloud-based LMS. The remaining $1 / 3^{\text {rd }}$ of the librarians are not aware of cloud-based LMS. Slowly the world moving towards cloud computing, there is no doubt the scenario of academic libraries in India would change shortly. Many vendors such as Informatics, Orizin, Libsys, Libsoft, eGranthalaya, etc. are providing cloud-based LMS 
services in India. Techno-savvy users are also demanding the libraries to provide cloud-based services. VTU, which is always at the forefront to help the academic fraternity by providing the online resources through VTU Consortium, should come forward to develop a centralized cloud-based LMS to help its affiliated college libraries to cater the needs of end users mainly the students and the faculty. This will help the VTU affiliated college libraries to have a cloudbased LMS in a cost-effective style alongside with promoting high-end technologies.

\section{Source of Funding}

None.

\section{Conflict of Interest}

None.

\section{References}

1. Chandra, D. G., Kathing, M., \& Kumar, D. P. (2013). Library Automation in Cloud. 5th International Conference on Computational Intelligence and Coomunication Networks, 474-478. Mathura: IEEE.
2. Kleinrock, L. (2003). An Internet vision: The invisible global infrastructure. Ad Hoc Networks, 1(1), 3-11.

3. Library automation. (1996). The Electronic Library, Vol. 14, pp. 225-229. https://doi.org/10.1108/eb045472

4. McCarthy J. The Beginnings at MIT. IEEE Ann History Computing, 1992;14(1), 1-16.

5. Mell, P., \& Grance, T. (2011). National Institute of Standard and Technology (NIST). https://doi.org/https://doi.org/10.6028/NIST.SP.800-145

6. Pandya, M. (2012). Cloud computing for libraries: A SWOT analysis. Building Participatory Library Services in Digital Era, 387-394. Gangtok: INFLIBNET and Sikkim University.

7. Romero, N. L. "Cloud computing" in library automation: Benefits and drawbacks. Bottom Line: Managing Libr Finances. 2012;25(3), 110-4.

8. Understanding MARC Bibliographic: Parts 1 to 6. (2005). Retrieved April 2, 2020, from https://www.loc.gov/marc/umb/um01to06.html

9. Vocabulary.com. (2020). Retrieved April 14, 2020, from https://www.vocabulary.com/dictionary/automated

How to cite: Kantharaja CT, Bharathi V. Awareness of cloud-based library management software (LMS) in VTU engineering college libraries. Indian J Libr Sci Inf Techno 2020;5(1):12-5. 